\title{
Posttraumatic Stress Disorder and Associated Factors Among Drivers Surviving Road Traffic Crashes in Southwest Ethiopia
}

This article was published in the following Dove Press journal: Neuropsychiatric Disease and Treatment

\author{
Arefayne Alenko' \\ Hiwot Berhanu ${ }^{2}$ \\ Amare Abera Tareke (iD ${ }^{2}$ \\ Wondu Reta $\mathbb{D I}^{2}$ \\ Moyeta Bariso ${ }^{2}$ \\ Elias Mulat ${ }^{2}$ \\ Chala Kenenisa ${ }^{2}$ \\ Wondwossen Debebe ${ }^{2}$ \\ Kumale Tolesa ${ }^{3}$ \\ Shimelis Girma (1D) \\ 'Department of Psychiatry, Faculty of \\ Medical Science, Institute of Health, \\ Jimma University, Jimma, Ethiopia; \\ ${ }^{2}$ Department of Biomedical Sciences, \\ Faculty of Medical Science, Institute of \\ Health, Jimma University, Jimma, \\ Ethiopia; ${ }^{3}$ Department of Ophthalmology, \\ Faculty of Medical Science, Institute of \\ Health , Jimma University, Jimma, Ethiopia
}

Background: Road traffic crashes (RTCs) can cause serious and long-lasting consequences for drivers, both in terms of physical and mental health outcomes. Posttraumatic stress disorder (PTSD) is the most frequent mental disorder occurring after traumatic exposure. Ethiopian drivers experience RTCs more frequently than other sub-Saharan countries. Despite this prevailing phenomenon, limited attention has been given to PTSD among drivers.

Objective: To determine the prevalence of PTSD and associated factors among drivers surviving RTCs in southwest Ethiopia.

Methods: A cross-sectional quantitative study was conducted among 402 male drivers who had survived RTCs. The study was conducted in Jimma zone, southwest Ethiopia from March to June, 2019. All drivers who had survived RTCs in the last year were included in the study. The Trauma Screening Questionnaire was used to determine the prevalence of PTSD. Data were entered in EpiData 3.1 and exported to SPSS 24 for analysis.

Results: The response rate of the study was 398(99\%). Fifty of $398(12.6 \%, 95 \%$ CI $9.5 \%-$ $16.1 \%$ ) met PTSD criteria based on the questionnaire. A history of near-miss RTCs (AOR 3.49, 95\% CI 1.89-6.43), depression (AOR 3.32, 95\% CI 1.36-5.12), and severe-risk cannabis use (AOR 2.51, 95\% CI 1.96-7.52) were significantly associated with PTSD.

Conclusion and recommendation: The prevalence of PTSD among drivers surviving RTCs was high compared to the general population. A record of near-miss RTCs, depression, and severe-risk cannabis use shown significant associations with PTSD. Strategies and guidelines must be developed to screen and treat PTSD among drivers surviving RTCs. Drivers with experience of near-miss RTCs, depression, and severe-risk cannabis use should be given priority when screening for PTSD.

Keywords: stress disorders, posttraumatic, traffic crash, prevalence, drivers, Ethiopia

\section{Introduction}

A road traffic crash (RTC) is a crash originating from, terminating with, or involving a vehicle partially or fully on a public road that results in property damage, morbidity, and mortality. ${ }^{1}$ RTCs nowadays are becoming a global public health concern, especially in low- and middle-income countries. According to a World Health Organization (WHO) report in 2015, Ethiopia is one of the 50 countries with the deadliest roads in the world. ${ }^{2}$ According to the report, RTCs kill more people in African countries and most other sub-Saharan countries than malaria does. RTC fatalities are predicted to be the second-leading cause of disability-adjusted life-years lost ( $>85 \%$ of all fatalities and $90 \%$ of disability-adjusted life-years) in developing countries, most of which are
Correspondence: Arefayne Alenko Jimma University, Institute of Health, Department of Psychiatry, Faculty of Medical Science, Institute of Health, Jimma University, Jimma, Ethiopia Tel +25I 967670149

Email arefeaynealenko@gmail.com 
African, by the year $2020 .{ }^{3,4}$ More than $90 \%$ of road traffic deaths occur in low- and middle-income countries. RTCs are the leading cause of death for those aged 5-29 years, and $73 \%$ of all road traffic deaths occur among young males aged $<25$ years, who are almost three times as likely to be killed. ${ }^{5}$

According to a study in northern Ethiopia, from 2007 to 2011 there are 9,255 RTCs registered in the region. A total of 2,761 people died due to the accidents, while 9,062 were severely and mildly injured. ${ }^{6}$ A study conducted in Burayu, central Ethiopia from July 2010 to June 2015 showed that 533 RTCs resulted in the death of $117(25 \%)$ and injured $345(75 \%){ }^{7}$ In 2019 , RTCs were the second-most common form of accidents and injuries, accounting for $22.8 \%$ of incidents. RTCs contributed to $43.8 \%$ of all fatalities, secondary to falling accidents and fighting injuries. Among RTC causalities, $21.9 \%$ were drivers. ${ }^{8}$ As such, drivers are highly affected by RTCs compared to the general population.

RTCs can have serious and long-lasting consequences for survivors, including drivers, both in terms of physical and mental health outcomes. ${ }^{4,9}$ RTCs have the capacity to provoke anxiety and fear in response to the experience or witness of trauma and finally result in full blown posttraumatic stress disorder (PTSD). ${ }^{10}$ According to the fifth edition of the Diagnostic and Statistical Manual of Mental Disorders, diagnosis of PTSD is primarily based on recurrent and distressing memories and dreams, persistent avoidance of stimuli associated with the traumatic event, marked sleep difficulty, and hypervigilance. Although PTSD can begin immediately after a traumatic event, it is not diagnosed unless the symptoms last for at least 1 month after trauma and cause either significant distress or functional disability. PTSD occurs in people of any age, sex, and nationality who have been exposed to life-threatening or horrifying events. ${ }^{11}$ The lifetime prevalence of PTSD in the general population ranges from $1.3 \%$ in Japan ${ }^{12}$ to $2.3 \%$ in South Africa. ${ }^{13}$

PTSD can occur due to deep unconscious intrapsychic conflict resulting from exposure to an overwhelmingly stressful event, such as RTCs. ${ }^{11}$ Epidemiological studies have found that most RTCs survivor, including drivers, develop PTSD. ${ }^{14-18}$ The prevalence of PTSD among a group of Iranian commercial motor vehicle drivers was $19.2 \%{ }^{14}$ The 1-year prevalence of PTSD among South Korean subway drivers was 5.6\%. ${ }^{15}$ A meta-analysis showed that the pooled prevalence of PTSD among RTC survivors was $22.25 \%$. In that study, PTSD prevalence varied from $6.3 \%$ to $58.3 \% .{ }^{17}$ The prevalence of PTSD was found to be $22.8 \%$ among survivors of RTCs in public hospitals in Addis Ababa, Ethiopia. ${ }^{18}$ Prevalence rates of PTSD following RTCs vary from $5.6 \%$ to $45 \% .{ }^{14-18}$

Not all individuals exposed to RTCs develop PTSD, ${ }^{11}$ and injury severity is not associated with PTSD.${ }^{19}$ Rather, there are risk factors that are associated with the development of PTSD. These are female sex, having poor social support, time since accident (1-3 months), and depression. ${ }^{18}$ Higher age and job experience and history or familial history of psychiatric disorders are also predictors of developing PTSD. The disease is more prevalent among those with a beginner's driving license. ${ }^{14}$ Drivers experiencing a sudden stop due to an emergency bell and with a history of a near accident have increased risk of PTSD. ${ }^{15}$

Untreated PTSD can cause long-term morbidity, functional impairments, and decreased quality of life in terms of health, productivity, and social interaction. ${ }^{11-13}$ The disorder is associated with such comorbidities as depression and substance abuse, and results in significant economic burden. ${ }^{11,12}$ Despite this burden, there has been limited research on the prevalence of PTSD and associated factors among drivers who have survived RTCs in subSaharan countries. Therefore, this study intended to fill this gap by assessing the prevalence and associated factors of PTSD among drivers who had survived RTCs. This would also help to integrate the mental health status of drivers in the Employers' Liability Act for make early diagnosis and timely treatment of PTSD.

\section{Methods}

\section{Study Design and Period}

A cross-sectional quantitative study was conducted in Jimma zone, southwest Ethiopia from March to June 2019.

\section{Study Area and Setting}

This study was conducted in Jimma zone, which is located $352 \mathrm{~km}$ southwest of Addis Ababa, the capital of Ethiopia. According to a 2007 Ethiopian central statistics report, the population of Jimma was $2,486,155$, of whom $1,250,527$ were men and 1,235,628 women. $^{20}$ otal Registered and licensed drivers of public transport under Jimma Zone Transport Authority numbered 6,046: bus and minibus drivers 4,446 , three- wheel vehicle (bajaj) drivers 1,352 , and taxi drivers 248 .

\section{Study Population}

Drivers working in public transport in Jimma from July 2018 to May 2019 numbered 6,046. Of these, 402 
had experienced an RTC and survived it in that period (Jimma Zone Transport Authority). All these 402 were included in the study (Figure 1). Drivers who had at least 1 year's experience driving and had had mild, moderate, or severe RTCs at least 1 month prior to the study registered on road traffic police reports were included. Drivers who were imprisoned or had left Jimma were excluded.

\section{Variables}

The outcome variable was PTSD. Independent variables were age, marital status, education, driving experience, income, work schedule, hospitalization after accident, death witnessed, time since accident, history of actual RTCs, history of near-miss RTCs, depression, history of mental illness, family history of mental illness, chronic physical illness, alcohol-use risk, khat-use risk, tobaccouse risk, and cannabis-use risk.

\section{Data-Collection Instrument}

Data were collected using structured self-administered questionnaires. A questionnaire was prepared in English, translated to the local language Oromo, and back-translated to check whether it had been translated correctly and was understandable to the data collectors. Sociodemographic questionnaires were used to assess drivers' background information. The Trauma Screening Questionnaire (TSQ) was used to determine the presence of PTSD. The TSQ is a ten-item symptom screen that was designed for use with survivors of all types of traumatic stress, including RTCs, and is based on items from the PTSD Symptom Scale — Self Report, and has

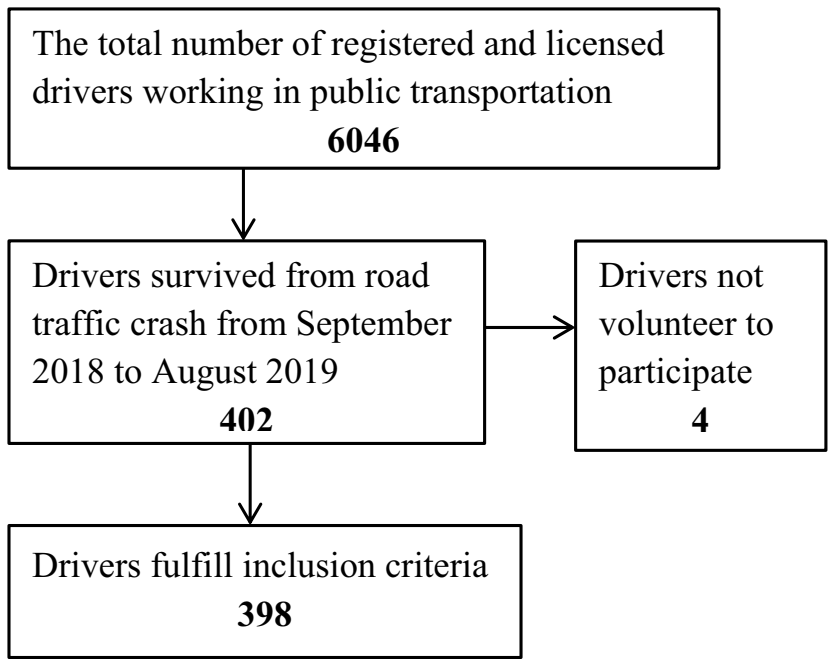

Figure I Flowchart of selection process of drivers surviving road traffic crashes in southwest Ethiopia, $2019(n=398)$. five "reexperiencing" items and five "arousal" items. PTSD is "positive" when at least six items are endorsed. ${ }^{21}$ The TSQ is an effective means to screen PTSD, with sensitivity of 0.85 and specificity $0.89 .^{22}$ Interrater reliability $(\kappa)$ of the TSQ in this study was 0.73 . Substance-use risk was assessed using the WHO Alcohol, Smoking, and Substance Involvement Screening Test version 3.1. ${ }^{23}$ The test's risk score ranges 0 31 for tobacco and 0-39 for alcohol and khat (amphetaminelike substance). Total score ranges are for alcohol are 0-10 (low risk), 11-26 (moderate), and $\geq 27$ high risk). Total risk scores for khat, tobacco, and cannabis are similar: low 0-3, moderate 4-26, and high $\geq 27 .{ }^{24}$ The Self-Reporting Questionnaire 20 was used to assess depression among drivers. This was developed by the WHO primarily to screen common mental disorders in developing countries, ${ }^{25}$ has sensitivity of $73 \%$, specificity $82 \%$, and interrater reliability ( $\kappa) 0.79,{ }^{26}$ and a total score $\geq 8$ is considered to represent depression. $^{25}$ A near-miss RTC is defined as an event/crash that does not result in physical injury or property damage. Drivers having such an event in the past were considered to have a history of near-miss RTCs. A questionnaire was developed to assess accident-related and clinical factors among drivers. Drivers were approached for data collection at their stations based on information given by the transport office of Jimma zone, town, and district and drivers' associations.

\section{Data Analysis}

Data were entered and cleaned using EpiData 3.1 and exported to SPSS 24 for analysis. Descriptive statistics are used to summarize the data and graphs, and statistical summary measures are used for presentation. After getting an overview of the data, simple binary logistic regression was fitted for each explanatory variable, and those variables with $p<0.25$ were fitted in multiple logistic regressions to get AORs with $95 \%$ CIs to identify factors associatedwith (PTSD. $p<0.05$ was considered statistically significant.

\section{Ethical Considerations}

Ethical clearance was obtained from the Jimma University Ethical Review Board. Formal letters were obtained from Jimma Zone Transport Authority and the respective district offices. Written consent was obtained from each participant before data collection. Study participants were informed about the research and their right to cease their involvement at any time. All information was kept confidential. 


\section{Results}

\section{Sociodemographic and Economic}

\section{Characteristics}

The response rate was $99 \%(n=398)$. The mean age of respondents was $32.11 \pm 9.133$ (20-60 years). Among the respondents, $119(30 \%)$ were in aged 20-30 years. More than half the respondents were married $(214,53.8 \%)$ and had completed primary education $(218,54.8 \%)$. The majority of drivers $(238,59.8 \%)$ had a monthly income of ETB2,000-3,000 and driving experience of 1-5 years $(238,59.8 \%)$. Most drivers worked day shifts $(262,65.8$, Table 1$)$.

\section{Accident-Related and Clinical Factors}

Regarding accident-related characteristics, the majority of drivers $(267,68.6 \%)$ had been hospitalized after an

Table I Sociodemographic and Economic Characteristics of Drivers Surviving Road Traffic Crashes in Southwest Ethiopia, $2019(n=398)$

\begin{tabular}{|c|c|c|c|}
\hline Variables & Categories & Frequency & Percentage \\
\hline Age (years) & $\begin{array}{l}20-30 \\
3 I-40 \\
4 I-50 \\
5 I-60\end{array}$ & $\begin{array}{l}119 \\
96 \\
110 \\
73\end{array}$ & $\begin{array}{l}30.0 \\
24.1 \\
27.6 \\
18.3\end{array}$ \\
\hline Marital status & $\begin{array}{l}\text { Married } \\
\text { Single } \\
\text { Widowed/ } \\
\text { divorced }\end{array}$ & $\begin{array}{l}214 \\
174 \\
10\end{array}$ & $\begin{array}{l}53.8 \\
43.7 \\
2.5\end{array}$ \\
\hline Education & $\begin{array}{l}\text { Primary } \\
\text { school } \\
\text { High school } \\
\text { graduate } \\
\text { Higher } \\
\text { institution }\end{array}$ & $\begin{array}{l}218 \\
154 \\
26\end{array}$ & $\begin{array}{l}54.8 \\
38.7 \\
6.5\end{array}$ \\
\hline $\begin{array}{l}\text { Driving experience } \\
\text { (years) }\end{array}$ & $\begin{array}{l}1-5 \\
5-10 \\
11-15 \\
16-20 \\
21-25\end{array}$ & $\begin{array}{l}219 \\
112 \\
35 \\
16 \\
16\end{array}$ & $\begin{array}{l}55.0 \\
28.1 \\
8.8 \\
4.0 \\
4.0\end{array}$ \\
\hline $\begin{array}{l}\text { Average monthly } \\
\text { income (ETB) }\end{array}$ & $\begin{array}{l}2,000-3,000 \\
3,00 I-4,000 \\
4,00 I-5,000 \\
5,00 I-6,000\end{array}$ & $\begin{array}{l}238 \\
77 \\
53 \\
30\end{array}$ & $\begin{array}{l}59.8 \\
19.3 \\
13.3 \\
7.6\end{array}$ \\
\hline Work schedule & $\begin{array}{l}\text { Day shift } \\
\text { Night shift } \\
\text { Irregular }\end{array}$ & $\begin{array}{l}262 \\
23 \\
114\end{array}$ & $\begin{array}{l}65.8 \\
5.5 \\
28.6\end{array}$ \\
\hline
\end{tabular}

Note: US\$1=ETB29. accident, a third $(124,31.1 \%)$ had witnessed the death of someone during accident/crash, 87 (21.8\%) had had actual RTCs, and 121 (31.1\%) had had near-miss RTCs. In addition, $255(65.6 \%)$ were interviewed 1-3 months after experiencing an RTC. From the total study participants, $104(26.1 \%)$ had depression, $32(8.2 \%)$ had a history of mental illness, $21(5.4 \%)$ had a family history of mental illness, and $43(11.0 \%)$ had a history of chronic physical illness (Table 2).

\section{Substance-Use Risk}

Regarding alcohol-use risk, 124 (31.2\%) had moderate risk and $94(23.6 \%)$ severe risk. A third $(131,32.9 \%)$ and half $(191,48.0 \%)$ of respondents had severe- and moderate-risk khat use, respectively. In sum, 115 $(28.9 \%)$ and 97 (24.4\%) study participants had moderate- and severe-risk tobacco use, respectively. Regarding cannabis use, 68 (17.1\%) had moderate- and 31 (7.8\%) severe-risk cannabis use. (Table 3)

Table 2 Accident-related and Clinical Factors Among Drivers Surviving Road Traffic Crashes (RTCs) in Southwest Ethiopia, $2019(n=398)$

\begin{tabular}{|l|l|l|l|}
\hline Characteristics & Categories & Frequency & Percentage \\
\hline $\begin{array}{l}\text { Hospitalized after } \\
\text { accident }\end{array}$ & Yes & 267 & 67 \\
No & 131 & 33 \\
$\begin{array}{l}\text { Witnessed the death } \\
\text { of someone due to } \\
\text { accident }\end{array}$ & $\begin{array}{l}\text { Yes } \\
\text { No }\end{array}$ & $\begin{array}{l}98 \\
300\end{array}$ & 24.6 \\
\hline $\begin{array}{l}\text { Duration since } \\
\text { accident (in months) }\end{array}$ & $>3$ & & \\
\hline $\begin{array}{l}\text { History of actual } \\
\text { RTCs }\end{array}$ & Yes & 255 & 65.6 \\
\hline History of near-miss & Yes & 134 & 34.4 \\
RTCs & No & 277 & 21.8 \\
\hline Depression & Yes & 104 & 78.2 \\
\hline No & 294 & 30.4 \\
\hline History of mental & Yes & 32 & 83.9 \\
illness & No & 366 & 91.9 \\
\hline $\begin{array}{l}\text { Family history of } \\
\text { mental illness }\end{array}$ & Yes & 21 & $5.3 \%$ \\
\hline No & 377 & 94.7 \\
\hline $\begin{array}{l}\text { Chronic physical } \\
\text { diabetes mellitus) }\end{array}$ & Yes & 43 & 10.8 \\
\hline
\end{tabular}

Note: Near-miss RTCs = events or crashes that did not result in physical injury or property damage. 
Table 3 Substance-use Risk Among Drivers Surviving Road Traffic Crash in Southwest Ethiopia, $2019(n=398)$

\begin{tabular}{|l|l|l|l|}
\hline Variables & Categories & Frequency & Percentage \\
\hline Alcohol use & No/mild & 180 & 45.2 \\
& Moderate & 124 & 31.2 \\
& Severe & 94 & 23.6 \\
\hline Khat use & No/mild & 76 & 19.0 \\
& Moderate & 191 & 48.0 \\
& Severe & 131 & 33.0 \\
\hline \multirow{2}{*}{ Tobacco use } & No/mild & 186 & 46.7 \\
& Moderate & 115 & 28.9 \\
& Severe & 97 & 24.4 \\
\hline \multirow{2}{*}{ Cannabis use } & No/mild & 299 & 75.1 \\
& Moderate & 68 & 17.1 \\
& Severe & 31 & 7.8 \\
\hline
\end{tabular}

\section{Prevalence of Posttraumatic Stress Disorder}

Based on the TSQ, the prevalence of PTSD was found to be 50 (12.6\%, 95\% CI 9.5\%-16.1\%) among drivers who had survived an RTC. Among PTSD symptoms, heightened awareness of potential dangers or hypervigilance $(24.9 \%)$ and difficulty falling asleep (17.6\%) were highly prevalent (Figure 2).

\section{Factors Associated With Posttraumatic Stress Disorder}

Multivariate logistic regression revealed that a history of near-miss RTCs, depression, and severe-risk cannabis use had significant associations with PTSD. Drivers who had a record of near-miss RTCs were more likely to develop PTSD than who with no record of RTCs (AOR 3.49, 95\% CI 1.89-6.43), odds of developing PTSD among those with depression were 3.3 times higher than those without depression (AOR 3.32, 95\% CI 1.36-5.12), and drivers who had severe-risk cannabis use were 2.5 times as likely to develop PTSD than their counterparts (AOR 2.51, 95\% CI 1.96-7.52, Table 4).

\section{Discussion}

\section{Prevalence of Posttraumatic Stress Disorder}

In this study, the prevalence of PTSD among drivers surviving RTCs and its possible associations with different variables was assessed. The findings from the current study revealed a significant proportion of drivers who surviving RTCs had PTSD. The prevalence of PTSD was found to be
$12.6 \%$ (95\% CI 9.5\%-16.1\%) among drivers surviving RTCs. The findings of this study are in line with one done in Canada among bus drivers (14.3\%), ${ }^{27}$ and also agree with a studies conducted among RTC survivors attending orthopedic and trauma clinics in Kenya $(13.3 \%)^{28}$ and Cape Town $(12.2 \%){ }^{29}$ However, the proportion in this study was lower than others among a group of Iranian commercial motor-vehicle drivers (19.2\%), ${ }^{14}$ survivors of RTCs in public hospitals in Addis Ababa (22.8\%), ${ }^{18}$ and Nigerians $(26.7 \%){ }^{30}$ The magnitude of PTSD among drivers surviving RTCs varies widely as a result of the country of study, sample-size differences, the time point of PTSD screening and diagnosis, and tools used to assess PTSD, evidenced by the variation in PTSD prevalence in a metaanalysis. ${ }^{17}$ Contrarily, the finding of this study was higher than the 1-year prevalence of PTSD among South Korean subway drivers $(5.6 \%){ }^{15}$ A possible explanation for the observed differences could be the difference in tools used. The South Korean study used the Korean version of the Composite International Diagnostic Interview to screen PTSD, but the current study used the TSQ Also, the South Korean study conducted among all subway drivers, whereas the current study included only drivers who had survived RTCs.

\section{Factors Associated with Posttraumatic Stress Disorder}

This study revealed that factors associated with PTSD among drivers surviving RTCs were a record of near-miss RTCs, depression, and severe-risk cannabis use. The odds of developing PTSD among drivers who had a record of near-miss RTCs was three and a half times (AOR 3.49, 95\% CI 1.89-6.43) that of drivers with no records of near-miss RTCs. A near-miss RTC is when drivers are involved in an accident where they think they will die or be badly hurt, but are not. ${ }^{31}$ This can cause emotional harm and create disturbing reactions. Near-miss RTCs create persistent thoughts about the incident. When drivers face a moment of danger, the instinctive mechanisms of the brain and body create a state of high alert that prepares for survival. Drivers with near-miss RTCs also have heightened senses, which make them act instinctively (without thinking or reasoning) and react and make decisions much more quickly than usual, as there is no time for emotion or to make sense of the event. Due to this, drivers with near-miss RTCs are highly exposed to severe accidents and end up with PTSD. ${ }^{31}$ The other possible mechanism is that even though the threatened event or anticipated outcome of death or injury does 


\section{Percentage}

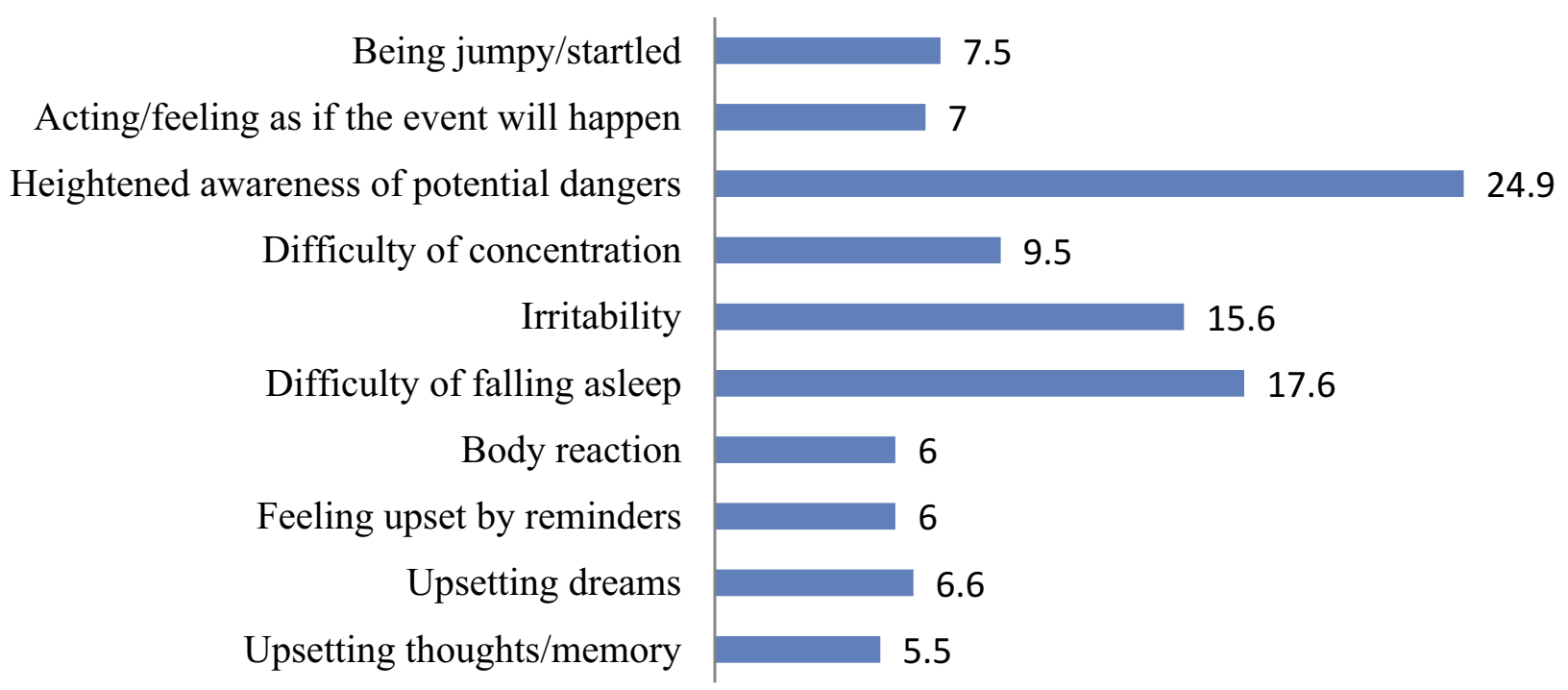

Figure 2 Prevalence of posttraumatic stress-disorder symptoms using Trauma Screening Questionnaire among drivers surviving road traffic crash in southwest Ethiopia, $2019(n=398)$.

not occur, the danger is replaced by unfamiliar and demanding experiences requiring mental health intervention. When this need for intervention is unmet, confusion reigns, leaving drivers stuck in that terrible moment deep down and putting them at risk of developing PTSD. This is supported by the study conducted among subway drivers in South Korea, in which having a history of a near-miss accident increased the risk of PTSD. $^{15}$

In addition, depression was significantly associated with the presence of PTSD in this study. The odds of developing PTSD among drivers with depression were 3.3 times (AOR 3.32, 95\% CI 1.36-5.12) higher than those without depression. This could be due to the fact that having another psychiatric diagnosis increases the risk of developing PTSD and poor long-term health outcomes, including impaired physical functioning and lower self-reported quality of life, may contribute. Preexisting untreated depression can put individuals at risk of PTSD when exposed to traumatic life events, such as RTCs. ${ }^{11}$ Comorbidity rates are high among individuals with PTSD, with about two-thirds having at least two other psychiatric disorders, such as major depressive disorder. ${ }^{32}$ The current finding was supported by studies conducted in Addis Ababa, ${ }^{18}$ Cape Town, ${ }^{29}$ and Nigeria. ${ }^{30}$

Furthermore, severe-risk cannabis use was found to be significantly associated with PTSD. The odds of developing PTSD among drivers with severe-risk cannabis use were 2.5 times (AOR 2.51, 95\% CI 1.96, 7.52) those with mild- and moderate-risk cannabis use. A possible reason is that individuals with PTSD use cannabis as self-medication. For example, it has been found that veterans with PTSD who also use cannabis say that cannabis is used specifically to reduce their PTSD symptoms, particularly intrusive thoughts and memories, sleep problems, and hyperarousal. ${ }^{33}$ In addition, studies have also found that PTSD symptoms are associated with cannabis use to cope with unpleasant emotions, such as anxiety and sadness. ${ }^{34}$

\section{Strengths and Limitations}

The study has a couple of strengths. First, it included all drivers from a well-defined catchment area. Second, we used the standardized instrument for measuring PTSD. A limitation of the study is that since the study assessed only drivers with RTCs, the results are difficult to generalize to drivers without RTCs. Other different traumas that could have occurred in drivers' lifetimes were not taken into account. Another limitation is that due to the crosssectional nature of the study, associations between different factors and PTSD do not imply cause and effect.

\section{Conclusion}

In the current study, the prevalence of PTSD among drivers surviving RTCs was high compared to the general population. A record of near-miss RTCs, depression, and severe-risk cannabis use showed significant associations with PTSD. Road and transport authorities should develop strategies and guidelines to screen and treat PTSD among drivers who have 
Table 4 Bivariate and Multivariate Analysis of Factors Associated with Posttraumatic Stress Disorder (PTSD) Among Drivers Surviving Road Traffic Crashes (RTCs) in Southwest Ethiopia, 2019 ( $n=398)$

\begin{tabular}{|c|c|c|c|c|c|c|}
\hline \multicolumn{2}{|l|}{ Variables } & \multicolumn{2}{|c|}{ PTSD } & \multirow{3}{*}{$\begin{array}{l}\text { COR }(95 \% \mathrm{Cl}) \\
4.49(1.49,7.50) \\
\end{array}$} & \multirow{3}{*}{$\begin{array}{l}\text { AOR }(95 \% \mathrm{Cl}) \\
3.31(0.96,5.66) \\
\end{array}$} & \multirow{3}{*}{$\begin{array}{l}\text { P-value } \\
0.130\end{array}$} \\
\hline & & \multirow{2}{*}{$\begin{array}{l}\text { Yes } \\
32 \\
9\end{array}$} & \multirow{2}{*}{$\begin{array}{l}\text { No } \\
186 \\
145\end{array}$} & & & \\
\hline Witnessed death during accident & $\begin{array}{l}\text { Yes } \\
\text { No }\end{array}$ & & & & & \\
\hline Duration since accident (months) & $\begin{array}{l}\mathrm{I}-3 \\
>3\end{array}$ & $\begin{array}{l}35 \\
15\end{array}$ & $\begin{array}{l}220 \\
119\end{array}$ & $\begin{array}{l}2.05(1.04,3.05) \\
1\end{array}$ & $\begin{array}{l}2.19 \\
1\end{array}$ & 0.078 \\
\hline Record of actual RTCs & $\begin{array}{l}\text { Yes } \\
\text { No }\end{array}$ & $\begin{array}{l}13 \\
37\end{array}$ & $\begin{array}{l}74 \\
290\end{array}$ & $\begin{array}{l}4.85(2.05,7.65) \\
\text { I }\end{array}$ & $\begin{array}{l}2.83(0.78,4.88) \\
\text { । }\end{array}$ & 0.072 \\
\hline Record of near-miss RTCs & $\begin{array}{l}\text { Yes } \\
\text { No }\end{array}$ & $\begin{array}{l}36 \\
14\end{array}$ & $\begin{array}{l}85 \\
263\end{array}$ & $4.00(1.65,6.36)$ & $\begin{array}{l}3.49(1.89,6.43) \\
1\end{array}$ & $0.034 *$ \\
\hline Depression & $\begin{array}{l}\text { Yes } \\
\text { No }\end{array}$ & $\begin{array}{l}37 \\
13\end{array}$ & $\begin{array}{l}67 \\
284\end{array}$ & $\begin{array}{l}6.01(2.82,9.21) \\
1\end{array}$ & $\begin{array}{l}3.32(1.36,5.12) \\
1\end{array}$ & $0.031 *$ \\
\hline History of mental illness & $\begin{array}{l}\text { Yes } \\
\text { No }\end{array}$ & $\begin{array}{l}20 \\
30\end{array}$ & $\begin{array}{l}12 \\
336\end{array}$ & $\begin{array}{l}2.18(0.90,5.23) \\
\text { I }\end{array}$ & $\begin{array}{l}2.43(0.5 \mathrm{I}, 4.35) \\
\mathrm{I}\end{array}$ & 0.757 \\
\hline Chronic physical illness & $\begin{array}{l}\text { Yes } \\
\text { No }\end{array}$ & $\begin{array}{l}11 \\
39\end{array}$ & $\begin{array}{l}32 \\
328\end{array}$ & $\begin{array}{l}3.36(1.76,4.97) \\
1\end{array}$ & $\begin{array}{l}2.98(0.95,5.01) \\
1\end{array}$ & 0.810 \\
\hline Alcohol-use risk & $\begin{array}{l}\text { Mild/none } \\
\text { Moderate } \\
\text { Severe }\end{array}$ & $\begin{array}{l}11 \\
15 \\
24\end{array}$ & $\begin{array}{l}169 \\
109 \\
107\end{array}$ & $\begin{array}{l}\text { I } \\
1.39(0.38,5.08) \\
2.80(1.50,5.22)\end{array}$ & $\begin{array}{l}\text { I } \\
0.39(0.38,4.08) \\
0.78(0.33,1.82)\end{array}$ & $\begin{array}{l}0.062 \\
0.570\end{array}$ \\
\hline Tobacco-use risk & $\begin{array}{l}\text { Mild/none } \\
\text { Moderate } \\
\text { Severe }\end{array}$ & $\begin{array}{l}15 \\
17 \\
18\end{array}$ & $\begin{array}{l}171 \\
98 \\
79\end{array}$ & $\begin{array}{l}3.49(1.89,6.43) \\
3.34(1.49,7.50) \\
2.18(0.90,5.23)\end{array}$ & $\begin{array}{l}1.55(0.69,3.49) \\
0.72(0.11,5.66) \\
I .49(0.51,4.357)\end{array}$ & $\begin{array}{l}0.291 \\
0.064 \\
0.141\end{array}$ \\
\hline Khat-use risk & $\begin{array}{l}\text { Mild/none } \\
\text { Moderate } \\
\text { Severe }\end{array}$ & $\begin{array}{l}10 \\
15 \\
25\end{array}$ & $\begin{array}{l}66 \\
176 \\
106\end{array}$ & $\begin{array}{l}\text { I } \\
0.78(1.03-3.05) \\
6.36(2.85,14.16)\end{array}$ & $\begin{array}{l}\text { I } \\
\text { I.80 }(0.93,3.46) \\
5.60(0.96,9.18)\end{array}$ & $\begin{array}{l}0.078 \\
0.054\end{array}$ \\
\hline Cannabis-use risk & $\begin{array}{l}\text { Mild/none } \\
\text { Moderate } \\
\text { Severe }\end{array}$ & $\begin{array}{l}18 \\
16 \\
16\end{array}$ & $\begin{array}{l}281 \\
52 \\
15\end{array}$ & $\begin{array}{l}\text { I } \\
3.49(1.89,6.43) \\
5.10(2.82,9.21)\end{array}$ & $\begin{array}{l}\text { I } \\
\text { I.55 }(0.69,3.49) \\
2.5 \mathrm{I}(1.96,7.52)\end{array}$ & $\begin{array}{l}0.291 \\
0.03 *\end{array}$ \\
\hline
\end{tabular}

Notes: I = constant; ${ }^{*} p<0.05$

survived RTCs, in order to improve the quality of life of drivers and to ensure passengers' safety in case they return to driving. Further research using diagnostic tools should be conducted to strengthen the current findings.

\section{Data-Sharing Statement}

The data sets used and analyzed during the current study are available from the corresponding author on reasonable request.

\section{Acknowledgments}

The authors acknowledge Jimma University Institute of Health for funding the study. The Jimma Zone Transport Office, study participants, and data collectors are also highly acknowledged.

\section{Author Contributions}

All authors contributed to data analysis and drafting and revising the article, gave final approval of the version to be published, and agree to be accountable for all aspects of the work.

\section{Ethics Approval and Consent to Participate}

Ethical approval was obtained from the Institutional Review Board of Jimma University Institute of Health. Drivers who agreed to participate gave written consent. Confidentiality was maintained by omitting identifiers from study tools, and privacy was ensured during interviews. Participants were informed that involvement in 
this study had no financial or political benefit, and would not affect their career (driving). All participants were given an information sheet, and were included in the study only after providing informed consent.

\section{Funding}

This research was funded by Jimma University Institute of Health.

\section{Disclosure}

The authors declare that they have no competing interests.

\section{References}

1. WHO. Global Status Report on Road Safety: Time for Action. Geneva: World Health Organization; 2009.

2. The Economist. Road deaths in Africa Worse than malaria. October 242015.

3. Nantulya VM, Reich MR. The neglected epidemic: road traffic injuries in developing countries. Br Med J. 2002;7346:1139. doi:10.1136/ bmj.324.7346.1139

4. Hassen A, Godesso A, Abebe L, Girma E. Risky driving behaviors for road traffic accident among drivers in Mekele city, Northern Ethiopia. BMC Res Notes. 2011;4(1):535. doi:10.1186/1756-05004-535

5. World Health Organization. Road traffic injuries. December 72018.

6. Mekonnen FH, Teshager S. Road traffic accident: the neglected health problem in Amhara National Regional State, Ethiopia. Ethiop J Health Dev. 2014;28(1):3-10.

7. Weldemarium TD. Prevalence of fatality and associated factors of road traffic accidents among victims reported to Burayu town police stations, between 2010 and 2015, Ethiopia. J Transp Health. 2018. doi:10.1016/j.jth.2018.06.007

8. Abegaz T, Gebremedhin S, Useche SA. Magnitude of road traffic accident related injuries and fatalities in Ethiopia. PLoS One. 2019;14 (1):e0202240. doi:10.1371/journal.pone.0202240

9. Gopinath B, Jagnoor J, Harris IA, et al. Comparison of health outcomes between hospitalised and nonhospitalised persons with minor injuries sustained in a road traffic crash in Australia: a prospective cohort study. BMJ Open. 2015;5(9):e009303. doi:10.1136/bmjopen2015-009303

10. Seid M, Azazh A, Enquselassie F, Yisma E. Injury characteristics and outcome of road traffic accident among victims at Adult Emergency Department of Tikur Anbessa Specialized Hospital, Addis Ababa, Ethiopia: a prospective hospital based study. BMC Emerg Med. 2015;15(1):10. doi:10.1186/s12873-015-0035-4

11. American Psychiatric Association. Diagnostic and Statistical Manual of Mental Disorders-Fifth Edition. Washington (DC): American Psychiatric Association; 2013.

12. Kawakami N, Tsuchiya M, Umeda M, et al. Trauma and posttraumatic stress disorder in Japan: results from the World Mental Health Japan Survey. J Psychiatr Res. 2014;53:157-165. doi:10.1016/j. jpsychires.2014.01.015

13. Atwoli L, Stein DJ, Williams DR, et al. Trauma and posttraumatic stress disorder in South Africa: analysis from the South African Stress and Health Study. BMC Psychiatry. 2013;13:182. doi:10.1186/1471-244X-13-182

14. Saberi HR, Abbasian H, Motalebi Kashani M, Naseri Esfahani AH. Post-traumatic stress disorder: a neglected health concern among commercial motor vehicle drivers. Int J Occup Environ Med. 2013;4:185-194.
15. Kim S-E, Kim H-R, Park J-I. The association between psychiatric disorders and work-related problems among subway drivers in Korea. Ann Occup Environ Med. 2014;26:39. doi:10.1186/s40557-014-00397

16. Craig A, Tran Y, Guest R, et al. Psychological impact of injuries sustained in motor vehicle crashes: systematic review and meta- analysis. $B M J$ Open. 2016;6:e11993. doi:10.1136/bmjopen-2016-011993

17. Lin W, Gong L, Xia W, et al. Prevalence of posttraumatic stress disorder among road traffic accident survivors. Systematic review and meta- analysis. Medicine. 2018;97:3. doi:10.1097/ MD.0000000000009693

18. Yohannes K, Gebeyehu A, Adera T. Prevalence and correlates of post-traumatic stress disorder among survivors of road traffic accidents in Ethiopia. Int J Ment Health Syst. 2018;12:50. doi:10.1186/ s13033-018-0229-8

19. Herrera-Escobar P, Al Rafai SS, Seshadri AJ, et al. A multicenter study of post-traumatic stress disorder after injury: mechanism matters more than injury severity. Surgery. 2018;164:1246-1250. doi:10.1016/j.surg.2018.07.017

20. Federal Democratic Republic of Ethiopia. Population Census Commission. Summary and Statistical Report of the 2007 Population and Housing Census Results. Addis Ababa; 2008.

21. Brewin C, Rose S, Andrews B, et al. Brief screening instrument for post-traumatic stress disorder. Br J Psychiatry. 2002;181:158-162. doi:10.1192/bjp.181.2.158

22. Walters J, Bisson JI, Shepherd JP, et al. Predicting post-traumatic stress disorder: validation of the Trauma Screening Questionnaire in victims of assault. Psychol Med. 2007;37:143-150. doi:10.1017/ S0033291706008658

23. Humeniuk R, Henry-Edwards S, Ali R, Poznyak V, Monteiro MGV. The Alcohol, Smoking and Substance Involvement Screening Test (ASSIST) Manual for Use in Primary Care. World Health Organization; 2010.

24. Newcombe D, Tanielu-stowers H, Mcdermott R, Stephen J, Nosa V. The validation of the Alcohol, Smoking and Substance Involvement Screening Test (ASSIST) amongst Pacific people in New Zealand. N Z J Psychol. 2016;45(1).

25. Beusenberg M, Orley JH, World Health Organization. Division of Mental Health. A User's guide to the self-reporting questionnaire (SRQ / compiled by M. Beusenberg and J. Orley). World Health Organization, 1994. Available from: https://apps.who.int/iris/handle/ 10665/61113. Accessed December 16, 2019.

26. Taun T, Harpham T, Huong NT. Validity and reliability of the self-reporting questionnaire 20 items in Vietnam. Hong Kong J Psychiatry. 2004;14(3):15-18.

27. Zhou B, Boyer R, Guay S. Dangerson the road: a longitudinal examination of passenger-initiated violence against bus drivers. Stress Health. 2018;34:253-265. doi:10.1002/smi.2779

28. Ongecha-Owuor F, Kathuku D, Othieno CJ, et al. Post traumatic stress disorder among motor vehicle accident survivors attending the orthopaedic and trauma clinic at Kenyatta National Hospital, Nairobi. East Afr Med J. 2004;81(7):362-366. doi:10.4314/eamj.v81i7.9192

29. Dickov A, Martinović-Mitrović S, Vučković N, et al. Psychiatric consequences of stress after a vehicle accident. Psychiatr Danub. 2009;21(4):483-489.

30. Iteke O, Bakare MO, Agomoh AO, et al. Road traffic accidents and posttraumatic stress disorder in an orthopedic setting in South-Eastern Nigeria: a controlled study. Scand J Trauma Resusc Emerg Med. 2011;19:39. doi:10.1186/1757-7241-19-39

31. Near-miss experiences and traumatic events, Better Health. Department of Health and Human Services - Emergency Management. Available from: www.betterhealth.vic.gov.au.Accessed December 6, 2019. State of Victoria. Reproduced from the Better Health Channel. Copyright (C) 1999/2019.

32. Kaplan \& Sadock's Synopsis of Psychiatry: Behavioral Sciences/ Clinical Psychiatry. 11th ed. Sadock, Pedro Ruiz; 2015. 
33. Wilkinson ST, Stefanovics E, Rosenheck RA. Marijuana use is associated with worse outcomes in symptom severity and violent behavior in patients with posttraumatic stress disorder. $J$ Clin Psychiatry. 2015;76:1-478. doi:10.4088/JCP.14m09475
34. Bettenhauser K, Pilz J, Vollmer LE. Use and effects of cannabinoids in military veterans with posttraumatic stress disorder. Am J Health Syst Pharm. 2015;72:1279-1284. doi:10.2146/ajhp140523

\section{Publish your work in this journal}

Neuropsychiatric Disease and Treatment is an international, peerreviewed journal of clinical therapeutics and pharmacology focusing on concise rapid reporting of clinical or pre-clinical studies on a range of neuropsychiatric and neurological disorders. This journal is indexed on PubMed Central, the 'PsycINFO' database and CAS, and is the official journal of The International Neuropsychiatric Association (INA). The manuscript management system is completely online and includes a very quick and fair peer-review system, which is all easy to use. Visit http://www.dovepress.com/testimonials.php to read real quotes from published authors.

Submit your manuscript here: https://www.dovepress.com/neuropsychiatric-disease-and-treatment-journal 